\title{
Alimentos orgânicos da agricultura familiar no Programa Nacional de alimentação Escolar do Estado de Santa Catarina, Brasil ${ }^{1}$
}

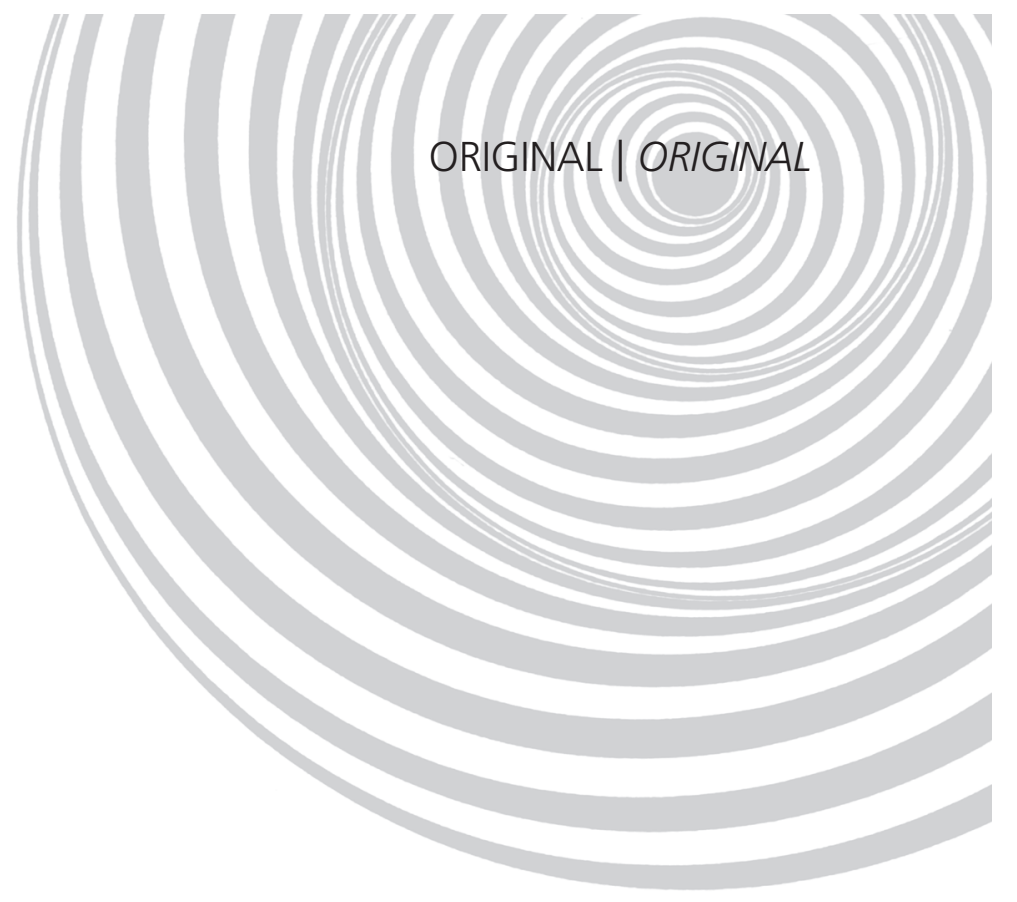

\author{
Organic foods from family farms in the \\ National School Food Program in the \\ State of Santa Catarina, Brazil
}

Ana Paula Ferreira da SILVA ${ }^{2}$

Anete Araújo de SOUSA ${ }^{2}$

RES U M O

\section{Objetivo}

Analisar a demanda e a oferta de alimentos orgânicos para a alimentação escolar no estado de Santa Catarina de acordo com a regulamentação do Programa Nacional de Alimentação Escolar.

\section{Métodos}

Estudo descritivo e exploratório. No ano de 2010 foi realizado um censo nos 293 municípios do estado por meio de questionário eletrônico para conhecer o percentual de compras de alimentos da agricultura familiar e de alimentos orgânicos. Posteriormente, foram entrevistados in loco alguns atores sociais da alimentação escolar de 52 municípios que compravam alimentos orgânicos da agricultura familiar. Os dados foram apresentados em números absolutos e relativos, com detalhamento por municípios.

\section{Resultados}

O destino da produção, em sua maioria, foi local e 17,7\% dos municípios compraram alimentos orgânicos da agricultura familiar no ano de 2010. Foram relatadas dificuldades tanto do nutricionista quanto dos agricultores familiares e das cooperativas. A maioria dos agricultores e cooperativas não tinha certificação de seus produtos

\footnotetext{
1 Artigo baseado na dissertação de APF SILVA, intitulada "Demanda e oferta de alimentos orgânicos da agricultura familiar para a alimentação escolar em municípios de Santa Catarina". Universidade Federal de Santa Catarina; 2012. Apoio: Fundo Nacional de Desenvolvimento da Educação, Processo no 234000.000675/2010-21 e Centro Colaborador em Alimentação e Nutrição do Escolar do Estado de Santa Catarina.

2 Universidade Federal de Santa Catarina, Centro de Ciências da Saúde, Departamento de Nutrição, Programa de Pós-Graduação em Nutrição. Campus Universitário, Sala 205, Trindade, 88040-970, Florianópolis, SC, Brasil. Correspondência para/ Correspondence to: AA SOUSA. E-mail: <sousa.anete@gmail.com>.
} 
702 | APF SILVA \& AA SOUSA

e enfrentava problemas de produção, revelando a necessidade de apoio técnico. Os nutricionistas ressaltaram a falta de certificação de agricultores e a baixa oferta de alimentos orgânicos. Para agricultores e cooperativas, as limitações na comercialização para a alimentação escolar foram a baixa procura por parte dos municípios, as dificuldades no transporte e a sazonalidade da produção. Apesar das dificuldades relatadas, os municípios catarinenses já adquirem frutas, verduras, legumes e outros alimentos.

\section{Conclusão}

Os alimentos da agricultura familiar orgânica produzidos localmente, já estão sendo incluídos na alimentação escolar. No entanto, ainda há necessidade de diálogo entre nutricionistas e agricultores familiares.

Termos de indexação: Agricultura orgânica. Alimentação escolar. Alimentos orgânicos. Planejamento de cardápio.

\section{A B S T R A C T}

\section{Objective}

To analyze the supply and demand of organic foods for the schools of Santa Catarina according to the National School Food Program regulation.

\section{Methods}

This is a descriptive and exploratory study. In 2010 an electronic questionnaire was used to investigate the percentage of organic and conventional foods purchased from family farms by 293 municipalities of Santa Catarina. Later, the school food buyers from 52 municipalities who bought organic foods from family farms were interviewed on-site. The data were expressed as absolute and relative numbers by municipality.

\section{Results}

Most foods were consumed locally, and $17.7 \%$ of the municipalities bought organic foods from family farms in 2010. Dieticians, farmers, and cooperatives experienced difficulties. Most farmers' and cooperatives' products were not certified, and the farmers experienced production problems, requiring technical support. Dieticians complained about the lack of product certification and low supply of organic foods. According to farmers and cooperatives, the limitations of selling to schools were the low demand, transportation difficulties, and product seasonality. Despite the difficulties, the municipalities in Santa Catarina are purchasing some fruits, vegetables, and other foods from family farms.

\section{Conclusion}

Organic locally-produced family farm products are included in school meals. However, dieticians and family farmers need to dialogue.

Indexing terms: Organic agriculture. School feedings. Foods organic. Menu planning.

\section{N T R O D U Ç Ã O}

O Programa Nacional de Alimentação Escolar (PNAE) é uma das estratégias de Segurança Alimentar e Nutricional (SAN) que se orientam pelos princípios do Direto Humano à Alimentação Adequada (DHAA) ${ }^{1}$. Em sua regulamentação, são destacadas orientações nutricionais para o escolar, visando o crescimento, o desenvolvimento, a aprendizagem e o rendimento escolar, além da promoção de hábitos alimentares saudáveis ${ }^{2}$.

As novas diretrizes de execução do PNAE foram estabelecidas por meio da Lei n 11.947/2009 e da Resolução 38, de julho de 20093,4. Uma delas estipula que, no mínimo, 30\% do total de recursos repassados pelo Fundo Nacional de Desenvolvimento da Educação (FNDE), ligado ao Ministério da Educação (MEC), devem ser destinados à compra de alimentos, preferencialmente orgânicos, produzidos pela agricultura familiar (local, regional ou nacional), dispensando o processo licitatório. A mencionada Resolução determina, ainda, que o cardápio escolar deve ser elaborado por nutricionista.

O apoio aos pequenos e médios produtores rurais e urbanos para a produção de alimentos locais é considerado essencial para a susten- 
tabilidade, considerando o atendimento de dimensões sociais (ocupação e renda de agricultores), ecológicas (diversidade e oferta de alimentos de qualidade), econômicas (menor custo com transporte) e culturais (confiabilidade do produto, preservação do hábito regional e da produção artesanal), promovendo uma conexão entre o rural e o urbano ${ }^{5,6}$. Destacam-se, ainda, as possibilidades de certificação dos produtos por meio de Sistemas Participativos de Garantia e do Controle Social na venda direta ${ }^{7}$.

Carvalho ${ }^{8}$, ao analisar experiências exitosas em municípios brasileiros, antes das novas diretrizes de execução do PNAE e referindo as licitações como sustentáveis, observou que a alimentação escolar tem promovido o desenvolvimento regional, a inclusão social, a movimentação da economia local, o consumo de alimentos mais frescos por parte dos escolares, a redução nos gastos com transportes e a promoção de educação alimentar e nutricional para além do espaço escolar.

Triches et al. ${ }^{6}$ e Turpin ${ }^{9}$ argumentaram que, diante da nova legislação, a alimentação escolar ganha reforços que estimulam os agricultores familiares. Além disso, beneficiam escolares e comunidade local, possibilitando discussões do PNAE relativos à produção e ao desenvolvimento rural e suas relações com o consumo e a saúde pública. No mesmo sentido, Real et al. ${ }^{10}$ encontraram benefícios na aproximação do pequeno produtor e comerciantes locais para a alimentação escolar.

Soares ${ }^{11}$, ao analisar outro programa governamental de apoio aos agricultores familiares, o Programa de Aquisição de Alimentos (PAA), em um município de Santa Catarina, constatou aumento da oferta e da variedade de hortaliças e frutas para a alimentação escolar. Além dos escolares, o programa beneficiou os agricultores familiares ao possibilitar a comercialização de alimentos locais.

Apesar dessas experiências, a articulação entre agricultores familiares e o mercado consumidor de alimentos, especialmente orgânicos, é um dos principais desafios para atingir os objetivos estabelecidos pelas novas diretrizes do PNAE. As análises sobre o uso de alimentos orgânicos mostram benefícios do consumo desse produto aos consumidores, ao meio ambiente e aos agricultores, bem como os limites da produção desses alimentos ${ }^{12,13}$.

O Programa Nacional de Alimentação Escolar, a partir das novas diretrizes, tornou-se um importante segmento institucional para aquisição de alimentos da agricultura familiar. Essa tarefa exige articulação entre quem compra (demanda de alimentos para as escolas do município) e quem vende (oferta de alimentos produzidos pelos agricultores familiares). Nesse espaço de interlocução, destaca-se que o planejamento dos cardápios escolares deve basear-se em novos referenciais: o de promoção da saúde conjugada à sustentabilidade ambiental, cultural, econômica e social.

Nesse contexto e em função do caráter recente da legislação, análises da compatibilidade entre a demanda e a oferta de alimentos orgânicos da agricultura familiar são necessárias, considerando o fortalecimento de ações relacionadas à produção e à compra de alimentos orgânicos e à saúde de populações vulneráveis como os escolares. Assim, esta pesquisa objetivou analisar a demanda e a oferta de alimentos orgânicos para a alimentação escolar em municípios do estado de Santa Catarina, Brasil, de acordo com a regulamentação do PNAE.

\section{M É T O D O S}

Foi realizado um estudo descritivo e exploratório que integra o projeto intitulado "Utilização de produtos provenientes da agricultura familiar e dos gêneros orgânicos na alimentação de escolares e sua interface com o Programa Nacional de Alimentação Escolar em municípios do Estado de Santa Catarina", desenvolvido pelo Centro Colaborador em Alimentação e Nutrição do Escolar do Estado de Santa Catarina (Cecane/SC), no ano de $2010^{14}$. 
A pesquisa realizada pelo Cecane/SC ocorreu em duas etapas. Na primeira, realizou-se um censo nos 293 municípios catarinenses, por meio de questionário eletrônico, para identificar o percentual de recursos do PNAE utilizados para compras de alimentos da agricultura familiar para a alimentação escolar e quais municípios compravam alimentos orgânicos. Na segunda etapa, foram entrevistados in loco atores sociais de municípios que compravam alimentos orgânicos da agricultura familiar para a alimentação escolar. Esses atores foram nutricionistas, diretores escolares ou coordenadores pedagógicos, merendeiras, agricultores familiares e cooperativas de agricultores, bem como Conselheiros de Alimentação Escolar (CAE). As duas etapas geraram dados de 63 municípios, dos quais nove foram excluídos por informações erradas sobre compra de alimentos orgânicos e dois por terem feito parte do estudo-piloto. Dessa forma, trabalhou-se com os dados de 52 municípios que compravam alimentos orgânicos da agricultura familiar para a alimentação escolar no estado de Santa Catarina, Brasil.

O instrumento de coleta de dados era constituído de várias questões. Neste estudo são apresentados e discutidos os resultados das variáveis referentes às questões sobre a demanda de alimentos orgânicos (aquisição de alimentos) obtidas pelo questionário do nutricionista e a oferta de alimentos orgânicos (comercialização de alimentos), obtidas do questionário dos agricultores e cooperativas de alimentos orgânicos da agricultura familiar.

Para compreender as variáveis demanda e oferta utilizaram-se os seguintes indicadores:

Variável demanda

- Elaboração de cardápios: profissional que elabora os cardápios das escolas.

- Lista de alimentos: características de alimentos presentes.

- Características de aquisição de alimentos orgânicos: compra de alimentos orgânicos; critérios utilizados para a seleção de fornecedores de alimentos orgânicos e dificuldades na utilização de alimentos orgânicos na alimentação escolar.
Variável oferta

- Características de aquisição de alimentos orgânicos: compra de alimentos orgânicos; critérios utilizados para a seleção de fornecedores de alimentos orgânicos; dificuldades na utilização de alimentos orgânicos na alimentação escolar.

- Lista de alimentos: outros alimentos orgânicos produzidos e que não estejam incluídos na lista. Listar espécies e variedades.

- Características de comercialização de alimentos orgânicos: início da comercialização de alimentos orgânicos com o município (mês/ano); número de municípios atendidos; identificação dos municípios e regiões e forma de seleção do agricultor/cooperativa de alimentos orgânicos para o município.

- Certificação de alimentos orgânicos: existência de certificação dos seus produtos. Se não: motivo(s) da não certificação.

- Dificuldade de comercialização de alimentos orgânicos para alimentação escolar: dificuldade na comercialização dos alimentos orgânicos com o município.

- Dificuldade na produção de alimentos orgânicos para aimentação escolar: dificuldade na produção dos alimentos orgânicos por parte dos agricultores desta cooperativa e possibilidade de aumento de produção de alimentos orgânicos para a alimentação escolar.

Os dados foram analisados por método estatístico descritivo, por meio de frequência absoluta e relativa.

A pesquisa foi aprovada pelo Comitê de Ética em Pesquisa com Seres Humanos da Universidade Federal de Santa Catarina sob o número 1005/2010.

\section{RESULTA DOS}

Constatou-se que em 2010, dentre os 293 municípios catarinenses, $60 \%$ ( $n=160)$ efetuavam compras de alimentos oriundos da agricultura familiar e desses, 17,7\% ( $n=52)$, compravam ali- 
mentos orgânicos. Destaca-se que dentre os 52 municípios, 6 também compravam alimentos orgânicos não provenientes da agricultura familiar. A região do Estado com maior percentual de municípios compradores foi a Região Sul (27,3\%, $n=12$ ). Entretanto, em relação ao número total de municípios que compravam atendidos, destaca-se a Região Oeste $(20,3 \%, n=24)$. Os percentuais das demais Regiões foram: Norte $(26,9 \%, n=7)$, Serrana $(16,7 \%, n=5)$, Vale do Itajaí $(5,6 \%, n=3)$ e Grande Florianópolis $(4,8 \%, n=1)$. $\mathrm{Na}$ análise dos critérios de seleção dos fornecedores para a alimentação escolar, no que concerne a agricultores familiares, 43,7\% ( $n=42)$ foram escolhidos por chamada pública; $37,5 \%(n=36)$ por consulta à lista de fornecedores conhecidos; 3,1\% $(n=3)$ não tiveram procedimento específico, 2,1\% $(n=2)$ por processo licitatório e 13,5\% ( $n=13)$ por outros tipos de processo.

Dentre os outros tipos de processos destacam-se contatos com grupos organizados (cooperativa, agricultores familiares ecológicos organizados, reunião com agricultores, cooperativas e sindicatos), contatos, convites ou reuniões com esferas ou programas governamentais (Secretaria da Agricultura, Secretaria de Educação, Programa de Aquisição de Alimentos - PAA), Prefeituras e Empresa de Pesquisa Agropecuária de Pesquisa e Extensão Rural de Santa Catarina (Epagri).

Quanto às cooperativas, $82,6 \%(n=19)$ foram selecionadas via chamada pública. Os outros critérios de seleção utilizados foram o processo licitatório; lista de fornecedores conhe- cidos, sem procedimento específico e/ou pregão eletrônico.

Na análise da procedência dos alimentos orgânicos para a alimentação escolar, constatou-se que os agricultores familiares e as cooperativas forneciam para o próprio município e Região. Apenas um agricultor da Região Oeste e uma cooperativa da Região Serrana ultrapassaram o âmbito regional, fornecendo para outras Regiões do Estado de Santa Catarina, e um agricultor da Região Sul fornecia também para outros Estados. Na Tabela 1 é apresentado o número de agricultores e cooperativas por Região, bem como o destino da produção de alimentos orgânicos (local, regional e/ou estadual). A Região Oeste do Estado apresenta o maior número de agricultores familiares e a Região Sul o maior número de cooperativas.

Ainda em relação ao destino da produção, $82,8 \%$ dos agricultores familiares vendem para um município, 10,7\% para dois municípios, 4,3\% para três municípios e 2,1\% para cinco municípios. Quanto às cooperativas, $34,8 \%$ vendem para um município, $13,0 \%$ para dois municípios, $26,1 \%$ para seis municípios, $13,0 \%$ para quatro municípios e 13,0\% para dez municípios.

Ao analisar o início da comercialização dos agricultores familiares para a alimentação escolar nos municípios avaliados, constatou-se que 5,3\% deles iniciaram a comercialização antes do ano de 2003; 30,8\% entre os anos de 2004-2008 e $63,8 \%$ entre 2009 e 2010. Das cooperativas anali-

Tabela 1. Destino da produção de alimentos orgânicos provenientes da agricultura familiar para o Programa Nacional de Alimentação Escolar, segundo os agricultores familiares e presidente das cooperativas. Santa Catarina, 2010.

\begin{tabular}{|c|c|c|c|c|c|c|c|c|c|}
\hline \multirow{3}{*}{ Região } & \multicolumn{5}{|c|}{ Agricultor $(n=93)$} & \multicolumn{4}{|c|}{ Cooperativa $(n=23)$} \\
\hline & \multicolumn{9}{|c|}{ Destino da produção } \\
\hline & $n$ & Local \% & Regional \% & Estadual \% & Outros Estados \% & $\mathrm{n}$ & Local \% & Regional \% & Estadual \% \\
\hline Grande Florianópolis & - & - & - & - & - & 1 & 100,0 & 100,0 & - \\
\hline Norte & 9 & 100,0 & - & - & & 4 & 100,0 & 75,0 & - \\
\hline Oeste & 66 & 97,0 & 19,7 & 1,5 & - & 6 & 100,0 & 50,0 & - \\
\hline Serrana & 6 & 100,0 & 1,5 & - & - & 2 & 100,0 & - & 50,0 \\
\hline Sul & 8 & 87,5 & 12,5 & - & 12,5 & 9 & 77,8 & 77,8 & - \\
\hline Vale do Itajaí & 4 & 100,0 & 25,0 & - & - & 1 & 100,0 & 100,0 & - \\
\hline
\end{tabular}


sadas, 4,5\% iniciaram a comercialização para o PNAE entre 2004-2008 e 95,4\% entre 2009-2010.

Dos municípios avaliados, 94,2\% ( $n=49)$ tinham seus cardápios elaborados por nutricionista responsável técnico e 5,8\% $(n=3)$ por outros profissionais (primeira dama; diretores, baseado no cardápio do nutricionista e secretário da agricultura juntamente com a coordenadora da alimentação escolar).

$\mathrm{Na}$ análise da aquisição dos alimentos orgânicos para o PNAE, 42,0\% dos nutricionistas relataram ter dificuldades nessa etapa (Tabela 2 ). O item "outros" correspondeu a 42,8\% e as respostas desses profissionais foram: baixa aceitação das merendeiras, baixa aceitação de alguns produtos, adversidades climáticas, capacidade de produção de alimentos por parte dos agricultores, resistência das merendeiras quanto à aparência dos produtos, grande oferta de determinados produtos em pequeno período do ano, dificuldades de comunicação entre os gestores, incoerências entre o pedido realizado e o produto recebido e sazonalidade.

As Tabelas 3 e 4 apresentam as principais dificuldades na produção e comercialização de alimentos orgânicos relatados pelos agricultores e cooperativas. O controle de pragas e doenças e as adversidades climáticas obtiveram maiores destaques. As cooperativas apontaram, ainda, o difícil acesso a informações sobre produção orgânica.

Dos agricultores familiares pesquisados, $66,7 \%$ ( $n=64)$ não possuíam certificação, 11,5\% $(n=11)$ eram certificados, $11,5 \%(n=11)$ estavam

Tabela 2. Dificuldades na utilização de alimentos orgânicos na alimentação escolar sob o ponto de vista dos nutricionistas. Santa Catarina, 2010

\begin{tabular}{lc}
\hline Dificuldades identificadas & Nutricionistas $(\mathrm{n}=50)$ \\
\hline Existe dificuldade na utilização de alimentos orgânicos na alimentação escolar (\% SIM) & 42,0 \\
Dificuldade em encontrar produtos no mercado & 33,3 \\
Produtores não possuem certificado para orgânicos & 33,3 \\
Dificuldade na logística de distribuição & 33,3 \\
Falta de capacitação & 28,6 \\
Preço dos produtos & 28,6 \\
Baixa qualidade dos produtos & 19,0 \\
Falta de documentação & 9,5 \\
Outros $^{*}$ & 42,8 \\
\hline
\end{tabular}

Nota: "Baixa aceitação das merendeiras, baixa aceitação de alguns produtos, adversidades climáticas, capacidade de produção de alimentos por parte dos agricultores, resistência das merendeiras quanto à aparência dos produtos, grande oferta de determinados produtos em pequeno período do ano, dificuldades de comunicação entre os gestores, incoerências entre o pedido realizado e o produto recebido e sazonalidade.

Tabela 3. Dificuldades na produção de alimentos orgânicos sob o ponto de vista dos agricultores e cooperativas. Santa Catarina, 2010.

\begin{tabular}{|c|c|c|}
\hline Dificuldadec identificadac & Agricultor $(n=88)$ & Presidente da Cooperativa $(n=24)$ \\
\hline Algum tipo de dificuldade na produção (\% SIM) & 57,3 & 95,8 \\
\hline Controle de pragas e doenças & 85,5 & 73,9 \\
\hline Adversidades climáticas & 81,8 & 82,6 \\
\hline Escassez de mão de obra & 60,0 & 56,5 \\
\hline Difícil acesso a informações sobre produção orgânica & 40,0 & 69,6 \\
\hline Difícil acesso a financiamentos para investimentos na produção & 25,5 & 30,4 \\
\hline Outros $^{*}$ & 21,8 & 34,8 \\
\hline
\end{tabular}

Nota: *Dificuldade na comercialização, preços baixos, baixa variedade cultivada, dificuldades para obter a certificação, falta de acesso a tecnologia, falta pesquisa de orgânicos pelo governo, criar projetos para solicitar financiamentos, pequena área da propriedade, falta valorização do produto e áreas vizinhas a plantação de orgânicos utilizando agrotóxicos. 
em processo de certificação e 10,41\% (n=10) não apresentaram esses dados. Quanto às cooperativas, 50,0\% ( $n=12)$ não possuíam certificação, $29,2 \%(n=7)$ tinham certificação, $16,7 \%(n=4)$ tinha certificação parcial e 4,2\% (n=1) estavam em processo de certificação.

Quanto ao tipo de certificação, $72,7 \%$ dos agricultores e $58,3 \%$ das cooperativas possuíam certificação participativa; $18,2 \%$ dos agricultores e $33,3 \%$ das cooperativas pelo sistema de auditoria e $9,1 \%$ dos agricultores eram certificados pelo Instituto Biodinâmico.

No Quadro 1 listam-se os alimentos adquiridos para a alimentação escolar e aqueles produzidos pelos agricultores familiares e cooperativas.

A possibilidade de aumento da produção foi ressaltada por $86,5 \%$ dos agricultores familiares. As principais dificuldades para aumentarem a produção (80\%) estão relacionadas com a escassez da mão de obra e a falta de área disponível. Já os aspectos menos expressivos foram a baixa procura por parte das prefeituras e o valor pago pelos produtos orgânicos.

\section{I S C U S S Ã O}

Os dados deste estudo mostraram que os municípios catarinenses, no ano de 2010, já esta- vam adquirindo preferencialmente alimentos orgânicos da agricultura familiar, conforme determina a Lei 11.947/2009 e a Resolução 38/20093,4. A Região do Estado de Santa Catarina que apresentou maior percentual de compras foi a Região Sul; no entanto, a que apresentou maior número de municípios atendidos foi a Região Oeste. Dados de Zoldan et al. ${ }^{18}$ mostraram que a Região Oeste de Santa Catarina é a que apresenta a maior concentração de agricultores familiares que produzem alimentos orgânicos, seguida da Região Sul, confirmando, portanto, os dados encontrados no presente estudo.

No Censo Agropecuário de 2006 do país, a Região Sul é a segunda maior em número de estabelecimentos e a quinta em área da agricultura familiar no Brasil ${ }^{19}$. Guilhoto et al. ${ }^{20}$ ressaltaram, ainda, que $44,0 \%$ do agronegócio familiar está na Região Sul do Brasil, decorrente do tipo de colonização e da herança cultural, onde os agricultores familiares se organizaram em associações, permitindo competir com outras propriedades rurais maiores.

Neste estudo, a chamada pública de compra foi a modalidade de seleção de grande parte dos agricultores familiares e cooperativas como fornecedores para a alimentação escolar, atendendo ao que preconiza a Resolução 38/20094.

Tabela 4. Dificuldades na comercialização de alimentos provenientes da agricultura familiar para a alimentação escolar do município sob o ponto de vista dos agricultores e cooperativas. Santa Catarina, 2010.

\begin{tabular}{lcc}
\hline Dificuldades identificadas & Pgricultor $(\mathrm{n}=95)$ & Presidente da Cooperativa $(\mathrm{n}=24)$ \\
\cline { 2 - 2 } & & 25,0 \\
\hline Algum tipo de dificuldade comercialização (\%SIM) & 32,3 & 60,0 \\
Baixa procura por parte dos municípios & 41,9 & 40,0 \\
Preços dos produtos & 35,5 & 60,0 \\
Dificuldades na produção & 22,6 & 20,0 \\
Dificuldades no transporte & 38,7 & 20,0 \\
Dificuldades nas negociações com o município & 32,3 & 40,0 \\
Demora para receber o pagamento & 22,6 & 40,0 \\
Sazonalidade da produção & 38,7 & 20,0 \\
Falta de documentação & 9,7 & 40,0 \\
Falta de capacitação & 25,8 & 40,0 \\
Outros & 22,6 & \\
\hline
\end{tabular}

Nota: *Dificuldade na comercialização, preços baixos, baixa variedade cultivada, dificuldades para obter a certificação, falta de acesso a tecnologia, falta pesquisa de orgânicos pelo governo, criar projetos para solicitar financiamentos, pequena área da propriedade, falta valorização do produto e áreas vizinhas a plantação de orgânicos utilizando agrotóxicos. 
Quadro 1. Variedades e diversidade de alimentos adquiridos pela alimentação escolar e produzidos pelos agricultores e cooperativas. Santa Catarina, 2010.

\begin{tabular}{|c|c|c|}
\hline Alimentos adquiridos pela alimentação escolar & Alimentos produzidos pelo agricultor & Alimentos produzidos pela cooperativa \\
\hline \multicolumn{3}{|c|}{ Frutas } \\
\hline $\begin{array}{l}\text { Abacate, abacaxi, amora, banana, caqui, figo }{ }^{\Delta} \text {, } \\
\text { goiaba, jabuticaba, kiwi, laranja, lichia }{ }^{\Delta} \text {, limão, } \\
\text { maçã, mamão, maracujá, melancia, mexerica, } \\
\text { morango, pêra, pêssego, physalis }{ }^{\Delta} \text { e uva. }\end{array}$ & $\begin{array}{l}\text { Abacate, abacaxi, ameixa+, banana, } \\
\text { caqui, carambola+, goiaba, jabuticaba, } \\
\text { laranja, limão, mamão, maracujá, me- } \\
\text { lão+, melancia, mexerica, morango, pêra, } \\
\text { pêssego, pitanga+e uva. }\end{array}$ & $\begin{array}{l}\text { Abacate, ameixa, amora, banana, } \\
\text { bergamota+, caqui, carambola+, goiaba, } \\
\text { jabuticaba, kiwi, laranja, limão, maçã, ma- } \\
\text { racujá, melão+, melancia, mexerica, } \\
\text { morgote, morango, nectarina, pêssego, } \\
\text { ponkan+ e uva. }\end{array}$ \\
\hline \multicolumn{3}{|c|}{ Sucos e polpas diversas } \\
\hline $\begin{array}{l}\text { Suco de } \text { uva }^{\Delta} \text { e polpa de: abacaxi }{ }^{\Delta} \text {, acerola }{ }^{\Delta} \text {, } \\
\text { butiá, laranja }{ }^{\Delta} \text {, maracujá, morango }{ }^{\Delta} \text { e uva }{ }^{\Delta} \text {. }\end{array}$ & - & Polpa de: butiá, butiá e açaí e maracujá. \\
\hline
\end{tabular}

Verduras e legumes

Abóbora, abobrinha, abóbora moranga, acelga, agrião, alface, alho, batata-doce, batata-inglesa, batata aipo (salsa), berinjela, beterraba, brócolis, cebola, cebolinha, cenoura, chicória, chuchu, couve mineira, couve flor, espinafre, inhame, mandioca, nabo, pepino, pimentão, rabanete, radiche ${ }^{\Delta}$, repolho, repolho roxo, rúcula, salsa e tomate.
Abóbora, abobrinha, abóbora moranga, acelga, agrião, alface, alface americana+ ${ }^{+}$ alface crespa+, alface mimosa, alho, almeirão+, batata-doce, batata-inglesa, batata aipo (salsa), berinjela, beterraba, brócolis, brócolis chinês+', cebola, cebolinha, cenoura, chicória, chuchu, couve mineira, couve-flor, espinafre, inhame, mandioca, nabo, pepino, pimentão, rabanete, repolho, repolho roxo, rúcula, salsa, tomate e tomate cereja+.

\begin{tabular}{|c|c|c|}
\hline \multicolumn{3}{|c|}{ Cereais } \\
\hline Arroz, milho, canjica, milho de pipoca. & Arroz, milho, canjica, milho de pipoca. & Arroz, milho e canjica. \\
\hline \multicolumn{3}{|c|}{ Leguminosas } \\
\hline $\begin{array}{l}\text { Feijão preto, feijão vermelho, feijão carioca, } \\
\text { feijão fradinho }{ }^{\Delta} \text {, ervilha, vagem, lentilha }{ }^{\perp} \text {. }\end{array}$ & 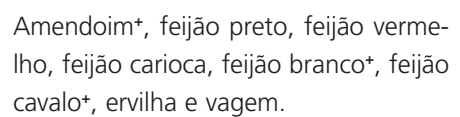 & $\begin{array}{l}\text { Amendoim+, feijão preto, feijão vermelho, } \\
\text { feijão carioca e ervilha. }\end{array}$ \\
\hline
\end{tabular}

Produtos processados*

Açúcar mascavo, leite, mel, melado, queijo, Açúcar mascavo, leite, manteiga+, mel, Açúcar mascavo, leite, mel, melado, iogurte, bebida láctea, doce de leite, pães, bola- melado, queijo, iogurte, bebida láctea, chas e biscoitos, geleia (chimia), massa caseira, doce de leite, pães, bolachas e biscoidoces caseiros (marmelada, goiabada, mariola), tos, geleia (chimia), massa caseira, dofarinha de milho, farinha de mandioca, cuca, ces caseiros (marmelada, goiabada, maconserva de cenoura ${ }^{\Delta}$, beterraba e pepino ${ }^{\Delta}$, pães riola), farinha de milho, farinha de manintegrais $^{\Delta}$, requeijão e rapadura ${ }^{\Delta}$. dioca, cuca, nata+, requeijão+, cana de

Abóbora, abobrinha, abóbora moranga, acelga, agrião, alface, alfavaca+, alho, almeirão+, batata-doce, batata-inglesa, berinjela, beterraba, brócolis, cebola, cebolinha, cenoura, chicória, chuchu, couve mineira, couve-flor, espinafre, inhame, mandioca, manjericão+, pepino, pimentão, rabanete, repolho, repolho roxo, rúcula, salsa, tomate e tomate cereja ${ }^{+}$. 
No entanto, Malina ${ }^{21}$ ao analisar as chamadas públicas no Estado de São Paulo, constatou alguns limites para o produtor: havia discrepância entre a demanda de produtos em relação à oferta e o cronograma de entregas era realizado conforme a necessidade dos municípios, sem considerar a oferta de produtos por parte do agricultor familiar.

Na seleção dos fornecedores, 2,1\% dos agricultores familiares foram selecionados por processo licitatório, embora a Lei n 11.947/2009³ dispense essa modalidade de procedimento para a compra da agricultura familiar. A chamada pública é o procedimento regulamentado pelo FNDE para esse tipo de compra ${ }^{3,4}$.

Belik et al.22 ao avaliarem a inclusão de alimentos da agricultura familiar na alimentação escolar constataram as mesmas dificuldades do presente estudo na aceitação das merendeiras aos produtos da agricultura familiar, por não possuírem um padrão uniforme no produto entregue.

O estudo de Souza ${ }^{23}$ destacou a importância dos nutricionistas e responsáveis pelos cardápios em considerarem a vocação agrícola da região e os limites de produção, como sazonalidade e problemas climáticos. Os nutricionistas entrevistados nesta pesquisa também destacaram a capacidade de produção e as adversidades climáticas como dificuldades.

Para isso, o planejamento requer a verificação das características dos diferentes produtos, pois os alimentos possuem ciclos produtivos diferentes (sazonalidade), interferindo no abastecimento. Ao mesmo tempo, os agricultores precisam realizar um planejamento da produção dos alimentos orgânicos de acordo com a demanda para reduzir as oscilações e garantir uma oferta estável de produtos ${ }^{13}$.

Alguns agricultores familiares entrevistados apontaram a falta de capacitação como uma das dificuldades do aumento de produção. A expectativa é de que o apoio seja realizado pelos órgãos públicos. Triches et al. ${ }^{6}$ constataram, no estudo realizado em Rolante e Dois Irmãos, no Rio Grande do Sul (RS), que as experiências exito- sas da compra de produtores locais foram possíveis pelo apoio da Assistência Técnica e Sindicatos Rurais, mostrando mais uma vez a importância desses órgãos no fomento à produção e comercialização de alimentos da agricultura familiar.

Na presente pesquisa constatou-se que a comercialização de alimentos de agricultores familiares e cooperativas para a alimentação escolar alcançou aumentos expressivos a partir da obrigatoriedade de compra da agricultura familiar. Ao analisar os dados relativos ao início da comercialização percebeu-se que houve aumento do número de agricultores envolvidos a partir de 2004. Isso pode ser decorrente do Programa de Aquisição de Alimentos (PAA), que permitiu maior acesso dos produtores à alimentação escolar antes da obrigatoriedade de compra da agricultura familiar estabelecida no ano de $2009^{4}$. Quanto às cooperativas, o aumento ocorreu a partir de 2009-2010, mostrando a importância da abertura de novos mercados institucionais a exemplo da alimentação escolar ${ }^{6,9}$.

Belik et al. ${ }^{22}$ ao avaliarem a inserção da agricultura familiar em São Bernardo (SP), apontaram que apesar das dificuldades encontradas para a execução da nova legislação, especialmente em municípios sem tradição agrícola, a articulação entre agricultores e gestores permitiu que as dificuldades encontradas inicialmente fossem superadas. Ou seja, de fato ocorreu um aumento na oferta de alimentos frescos e de melhor qualidade para a alimentação escolar e constatou-se uma melhoria nas condições de vida e de trabalho dos agricultores.

Ao analisar o destino de comercialização da produção dos agricultores e cooperativas, observou-se que foram comercializadas localmente e regionalmente, atendendo à Resolução 38/20094, indicando que a implementação de políticas públicas favorece o acesso dos agricultores familiares ao mercado institucional ${ }^{24}$. Além disso, pode atender progressivamente aos critérios de sustentabilidade - geração de trabalho e renda aos agricultores, redução do êxodo rural e pobreza rural e urbana ${ }^{10,25}$, proporcionando a criação de 
cadeias curtas de alimentos e a aproximação entre os produtores e consumidores ${ }^{26}$.

Apesar da possibilidade de novos mercados consumidores para os alimentos orgânicos, os agricultores familiares e as cooperativas enfrentam dificuldades em relação ao controle de pragas e adversidades climáticas. Para minimizar esse problema, são necessários investimentos no apoio técnico, por meio de órgãos públicos, orientandoos sobre como proceder nas adversidades sem utilização de agrotóxicos e como melhorar a produtividade de alimentos ${ }^{26}$.

Souza ${ }^{23}$, em um estudo realizado no Estado de São Paulo, a partir das novas diretrizes do PNAE, destacou dificuldades dos agricultores na comercialização para a alimentação escolar, tais como: obtenção da Declaração de Aptidão (DAP) ao Programa Nacional de Fortalecimento da Agricultura Familiar (Pronaf), exigências de controle sanitário e burocracia junto aos serviços de inspeção, ausência de assistência técnica ao agricultor para produzir alimentos mais variados, logística de abastecimento e, por último, a organização desses agricultores em associações ou cooperativas.

Nos municípios catarinenses avaliados neste estudo, a falta de documentação não foi apontada como um problema para o fornecimento de alimentos da agricultura familiar para a alimentação escolar. Entretanto, as dificuldades no transporte e na negociação com os municípios reforçam os dados encontrados por Souza ${ }^{23}$.

Em relação à elaboração de cardápios pelo nutricionista, os dados encontrados neste estudo são semelhantes aos de Chaves et al. ${ }^{27}$. Os autores observaram que, na Região Sul, 82,4\% dos cardápios analisados foram elaborados por nutricionistas. Ressalta-se, também, a necessidade desses profissionais ficarem atentos às exigências estabelecidas para a compra da agricultura familiar; fato este que orienta a realização de encontros com organizações de controle social, secretaria da agricultura, assistência técnica e rural e entidades da agricultura familiar ${ }^{22}$ para mapeamento dos alimentos produzidos para nortear a elaboração de cardápios.

Tendo em vista a formação de hábitos alimentares saudáveis, os cardápios da alimentação escolar devem englobar itens como: sazonalidade dos produtos, lista de substituição dos alimentos, articulação com agricultores familiares locais, inclusão de alimentos regionais e da cultura local. O planejamento do cardápio deve incluir alimentos da produção local e deve contribuir para o resgate da cultura alimentar regional, abrindo possibilidades para o desenvolvimento do município ${ }^{28}$.

Soares $^{11}$, ao analisar o PAA em um município de Santa Catarina, observou que a compra da agricultura familiar possibilitou maior variedade do cardápio servido nas escolas, especialmente de vegetais. Por outro lado, identificou dificuldades de fornecimento regular desses produtos, devido às alterações climáticas, sazonalidade e capacidade de produção. O estudo alertou para a possibilidade de substituições nos cardápios escolares, considerando os princípios da diversidade, variedade e menor disponibilidade de alimentos, o que aumentaria o número de produtos ofertados e de agricultores fornecedores.

Triches et al. ${ }^{6}$, nos municípios de Rolante e Dois Irmãos (RS), verificaram que houve a reformulação no cardápio para atender às especificações dos produtos da agricultura familiar para a alimentação escolar, favorecendo a aproximação entre oferta e demanda destes alimentos. No presente estudo, observou-se, pelos dados referentes às dificuldades de comercialização dos agricultores familiares e das cooperativas (baixa procura de alimentos orgânicos) e aquisição dos alimentos por parte dos nutricionistas (baixa disponibilidade de alimentos), que ainda há necessidade de maior articulação entre estes atores sociais no PNAE.

A certificação dos alimentos orgânicos apresentou baixa adesão. Os nutricionistas destacaram este aspecto como uma dificuldade para a aquisição dos alimentos orgânicos. Anjos et al. ${ }^{28}$, em um estudo sobre certificação solidária, verifi- 
caram que $56 \%$ dos entrevistados conheciam experiências de certificação. Desses, 67\% relataram que a certificação apresenta vantagens para a comercialização dos alimentos. Torres et al. ${ }^{29}$ observaram que o processo de certificação em uma cooperativa ocorreu pelo sistema de controle entre agricultores e seus filhos, para posterior certificação por órgão externos.

Recomenda-se que os agricultores familiares e as cooperativas se utilizem das certificações em grupo, por proporcionarem aos produtores um aumento nas possibilidades de comercialização e por terem seus custos reduzidos ${ }^{30}$. Outro mecanismo é a Organização de Controle Social (OCS) que é formada por um grupo, associação, cooperativa ou consórcio. Essa organização deve manter a lista de agricultores atualizada e, para que seja legalizada, necessita cadastrar-se em um órgão fiscalizador?

Os mecanismos de certificação participativa e o organismo de controle social aumentam a credibilidade do agricultor familiar e da cooperativa de produtores, em especial de alimentos orgânicos, no momento da comercialização, garantindo aos consumidores a procedência e a rastreabilidade dos produtos? ${ }^{7}$.

Em relação à diversidade e variedade de alimentos adquiridos pelos municípios catarinenses, observou-se que há alguns alimentos produzidos pela agricultura familiar e que não são adquiridos pela alimentação escolar, como: ameixa, melão, pitanga, carambola, nectarina, tomate cereja, molho de tomate, paçoca de pinhão, requeijão, manteiga entre outros.

Os alimentos regionais aparecem como os menos adquiridos e, também, como os que apresentam pouca produção por parte do agricultor familiar e suas cooperativas. Entende-se, contudo, que esse achado pode ser uma decorrência da limitação da lista de alimentos regionais utilizada no instrumento desta pesquisa, pois são escassos os estudos que mapeiam os alimentos regionais brasileiros. Um grupo de produtos adquiridos pelos nutricionistas que merece destaque são as conservas que fazem parte do hábito alimentar catarinense em virtude da colonização alemã.

Para este estudo utilizou-se o documento do Ministério da Saúde ${ }^{31}$ que considera como alimentos regionais catarinenses: o pinhão, o açaí de Jussara, o broto de bambu, a cebolinha, o nirá e o cará. No caso do pinhão, este alimento aparece como um produto adquirido pelos nutricionistas, mas referido pelos agricultores e/ou cooperativas como produto processado na forma de paçoca. Ressalta-se que esse é um produto nativo que faz parte do hábito alimentar catarinense, especialmente coletado por agricultores da região serrana.

O Guia Alimentar para a População Brasileira ${ }^{32}$ destaca a importância do consumo dos alimentos regionais para a garantia da segurança alimentar e nutricional. Outro aspecto é a importância da diversidade de alimentos, como ressalta o documento da Food and Agriculture Organization of the United Nations (FAO) sobre biodiversidade e sustentabilidade ${ }^{33}$. Nesse caso, os pequenos produtores são peças fundamentais para a manutenção da biodiversidade agrícola, ao utilizarem sistemas de produção sustentáveis respeitando a natureza e propondo modos de produção que busquem manter a biodiversidade agrícola ${ }^{33}$.

O estudo de Triches et al. ${ }^{6}$, Soares ${ }^{11} \mathrm{e}$ Schmitt et al. ${ }^{26}$, apontaram como benefícios da compra da agricultura familiar e do PAA o aumento da variedade de alimentos no cardápio das escolas, bem como a oferta de alimentos mais frescos e de melhor qualidade, promovendo a formação de hábitos alimentares mais saudáveis, valorizando a cultura regional e estimulando o comércio local de alimentos.

Quanto aos produtos adquiridos e produzidos pela agricultura familiar orgânica, constatou-se uma variedade de produtos já produzidos e incluídos no cardápio da alimentação escolar. Essa constatação reforça, mais uma vez, a necessidade do nutricionista seguir o que preconiza o instrumento governamental que determina a compra da agricultura familiar para a 
alimentação escolar, o qual estabelece que na elaboração do cardápio se conheça a diversidade, a variedade e a quantidade de gêneros que podem ser ofertados pelos agricultores. Isso poderá ser fortalecido por meio da aproximação entre gestores, agricultores e empreendedores familiares locais de alimentos.

\section{ONCLUS Ã O}

As novas diretrizes da alimentação escolar aumentaram as possibilidades de acesso dos agricultores familiares e das cooperativas para o fornecimento de alimentos por meio de chamadas públicas. Os resultados da aquisição da agricultura familiar de produção de alimentos orgânicos em Santa Catarina para a alimentação escolar apresentaram dados positivos, quais sejam: a compra de frutas, verduras, legumes, cereais e produtos processados. Outro ponto relevante foi a compra desses alimentos localmente, o que poderá estimular o comércio local e aumentar a diversidade e variedade de alimentos que possivelmente fazem parte do hábito alimentar.

Consideram-se importantes os resultados encontrados, especialmente por se tratar de uma avaliação no primeiro ano da obrigatoriedade de compra da agricultura familiar e por abranger todas as regiões do Estado de Santa Catarina. No entanto, enquanto os nutricionistas relataram dificuldades na oferta, ou seja, na disponibilidade de alimentos orgânicos para os agricultores e cooperativas, a principal dificuldade reconhecida por esta pesquisa, diz respeito à baixa demanda por tais alimentos. Essa incongruência nas declarações leva à conclusão de que, no Estado de Santa Catarina, ainda é necessária uma maior articulação entre os gestores, agricultores e cooperativas, especialmente entre nutricionistas e agricultores familiares e suas cooperativas, com o objetivo de conhecer quais são os alimentos que poderiam ser produzidos e quais poderiam ser adquiridos pela alimentação escolar, não apenas pela saúde dos escolares e pela importância de fomentar o comércio local, mas também para atender aos critérios de sustentabilidade na produção de alimentos.

A maioria dos agricultores e das cooperativas não tinha certificação de seus produtos e enfrentava problemas de produção, revelando a necessidade de apoio técnico para aumentar as possibilidades de comercialização dos alimentos orgânicos, não só para a alimentação escolar, mas também para outros mercados institucionais. A certificação participativa e as parcerias com organizações não governamentais e universidades podem ser estratégias para orientação e apoio aos agricultores familiares e às cooperativas.

Sugere-se a realização deste estudo em outros estados brasileiros, tendo em vista a importância dos alimentos orgânicos provenientes da agricultura familiar para a alimentação escolar, e também para avaliar a aplicação e a efetividade da recente legislação do PNAE (Resolução FNDE $n^{\circ}$ 26, de junho/2013), em substituição a Resolução FNDE n³8, de julho de 2009.

\section{A GRADECIMENTOS}

A parceria com o Centro Colaborador em Alimentação e Nutrição do Escolar do Estado de Santa Catarina (CECANE/SC) e ao Fundo Nacional de Desenvolvimento da Educação (FNDE) pelo financiamento da pesquisa.

\section{COLABORADORES}

APF SILVA e AA SOUSA participaram conjuntamente da concepção de desenho do artigo, da análise de dados, da redação e da revisão do texto.

\section{REFERÊ NCIAS}

1. Brasil. Conselho Nacional de Segurança Alimentar e Nutricional. Subsídios para a construção da política nacional de segurança alimentar e nutricional: documento elaborado pela comissão permanente 3. Brasília: Conselho Nacional de Segurança Alimentar e Nutricional; 2009 [acesso 2011 jul 15]. Disponível em: <http://www4. planalto. gov.br/consea/documentos/politica-e-sistema- 
nacional-de-seguranca-alimentar/documentosubsidios-para-a-construcao-da-politica-nacionalde-san>.

2. Brasil. Fundo Nacional de Desenvolvimento da Educação. Alimentação escolar, histórico. Brasília: Fundo Nacional de Desenvolvimento da Educação; 2009 [acesso 2011 abr 19]. Disponível em: <http:// www.fnde.gov.br/index.php/ae-historico $>$.

3. Brasil. Lei $n^{\circ} 11.947$, de 16 de junho de 2009. Dispõe sobre o atendimento da alimentação escolar e do programa dinheiro direto na escola aos alunos da educação básica. Diário Oficial da União. 2009 17 jun; p.2-4.

4. Brasil. Resolução/CD/FNDE $n^{\circ} 38,16$ de julho de 2009. Dispõe sobre o atendimento da alimentação escolar aos alunos da educação básica no Programa Nacional de Alimentação Escolar (PNAE). Brasília: Fundo Nacional de Desenvolvimento da Educação; 2009.

5. Brasil. Conselho Nacional de Segurança Alimentar e Nutricional. Princípios e diretrizes de uma política de segurança alimentar e nutricional: textos de referência da II Conferência de Segurança Alimentar e Nutricional. Brasília: Conselho Nacional de Segurança Alimentar e Nutricional; 2004 [acesso 2011 jun 29]. Disponível em: <http://www4. planalto. gov.br/consea/publicacoes/publiucacoes-arquivos/ principios-e-diretrizes-de-uma-politica-de-san>.

6. Triches RM, Schneider S. Alimentação escolar e agricultura familiar: reconectando o consumo à produção. Saúde Soc. 2010; 19(4):933-45. doi: 10.15 90/S0104-12902010000400019.

7. Brasil. Ministério da Agricultura, Pecuária e Abastecimentos. Mecanismos de controle para garantia da qualidade orgânica. Brasília: Ministério da Agricultura, Pecuária e Abastecimentos; 2009.

8. Carvalho DG. Licitações sustentáveis, alimentação escolar e desenvolvimento Regional: uma discussão sobre o poder de compra governamental a favor da sustentabilidade. Planej Pol Públicas. 2009; 32: 115-48.

9. Turpin ME. A alimentação escolar como fator de desenvolvimento local por meio do apoio aos agricultores familiares. Segur Aliment Nutr. 2009; 16(2):20-42.

10. Real LCV, Schneider S. O uso de programas públicos de alimentação na reaproximação do pequeno produtor com o consumidor: o caso do programa de alimentação escolar. Estud Debate. 2011; 18(2): 57-79.

11. Soares P. Análise do programa de aquisição de alimentos na alimentação escolar em um município de Santa Catarina [dissertação]. Florianópolis: Universidade Federal de Santa Catarina; 2011.
12. Lairon D. Nutritional quality and safety of organic food: A review. Agron Sustain Dev. 2009; 30(1): 33-41. doi: 10.1051/agro/2009019.

13. Brasil. Ministério da Agricultura, Pecuária e Abastecimento. Cadeia produtiva de produtos orgânicos. Brasília: Ministério da Agricultura, Pecuária e Abastecimento; 2007 [acesso 2011 abr 22]. Disponível em: <http://www.ibraf.org.br/x_files/Documentos/ Cadeia_Produtiva_de_Produtos_Org\%C3\%A2nicos_S\% C3\%A9rie_Agroneg\%C3\%B3cios_MAPA.pdf>.

14. Santa Catarina. Centro Colaborador em Alimentação e Nutrição do Escolar. Relatório das atividades desenvolvidas pela subcoordenação de pesquisa do CECANE/SC: abril a dezembro de 2010. Florianópolis: Centro Colaborador em Alimentação e Nutrição do Escolar; 2010.

15. Schneider, S. O papel da pluriatividade numa estratégia de desenvolvimento rural. In: Seminário Nacional de Desenvolvimento Rural Sustentável: textos para discussão. Brasília; Ministério do Desenvolvimento Agrário; 2005.

16. Brasil. Conselho Nacional do Meio Ambiente. Resolução CONAMA n 385, de 27 de dezembro de 2006. Estabelece procedimentos a serem adotados para o licenciamento ambiental de agroindústrias de pequeno porte e baixo potencial de impacto ambiental. Brasília: Conselho Nacional do Meio Ambiente; 2006.

17. Brasil. Ministério do Desenvolvimento Agrário. gerência de negócios e comercio: roteiro de elaboração de projetos agroindustriais para os territórios rurais. Brasília: Ministério do Desenvolvimento Agrário; 2007.

18. Zoldan P, Karam F. Estudo da dinâmica da comercialização de produtos orgânicos em Santa Catarina. Florianópolis: Instituto Cepa; 2004.

19. Instituto Brasileiro de Geografia e Estatística. Censo agropecuário 2006: agricultura familiar, primeiros resultados. Brasil, Grandes Regiões e Unidades da Federação. Rio de Janeiro: IBGE; 2006.

20. Guilhoto JM, Ichihara SM, Silveira FG, Gaiger F, Diniz BPC, Azzoni CR, et al. A Importância da agricultura familiar no Brasil e em seus estados. Anais do $35^{\circ}$ Encontro Nacional de Economia; 2007, Recife, Pernambuco. São Paulo: Anpec; 2007 [acesso 2012 abr 24]. Disponível em: <htpp://www.usp.br/ feaecon/ media/livros/file_459.pdf>.

21. Malina LL. Chamada pública: instrumento legal de compras da agricultura familiar para a alimentação escolar. In: Corá MAJ, Belik W, organizadores. Projeto Nutre SP: análise da inclusão da agricultura familiar na alimentação escolar no Estado de São Paulo. Brasília: Ministério do Desenvolvimento Agrário; 2012.

22. Belik W, Chaim NA. São Bernardo: atuação pioneira em favor da agricultura familiar. In: Corá MAJ, Belik 
W, organizadores. Projeto Nutre SP: análise da inclusão da agricultura familiar na alimentação escolar no Estado de São Paulo. Brasília: Ministério do Desenvolvimento Agrário; 2012.

23. Souza LBB. Organizações da agricultura familiar no Estado de São Paulo e sua experiência de fornecimento para o PNAE. In: Corá MAJ, Belik W, organizadores. Projeto Nutre SP: análise da inclusão da agricultura familiar na alimentação escolar no Estado de São Paulo. Brasília: Ministério do Desenvolvimento Agrário; 2012.

24. Maluf RS. Segurança alimentar e nutricional. Rio de Janeiro: Vozes; 2011.

25. Bonnal P, Maluf RS. Políticas de desenvolvimento territorial e multifuncionalidade da agricultura familiar no Brasil. Pol Soc. 2011; 8(14):211-50.

26. Schmitt CJ, Guimarães LA. O mercado institucional com instrumento para fortalecimento da agricultura familiar de base ecológica. Agriculturas. 2008; $5(2): 7$.

27. Chaves, LG, Mendes, PNR, Brito, RR, Botelho, RBA. O programa nacional de alimentação escolar como promotor de hábitos alimentares regionais. Rev Nutr. 2009; 22(6):857-66. doi: 10.1590/\$1415-52 732009000600007.

28. Anjos FS, Caldas NV, Trentin II. Desafios e possibilidades: certificação social e solidária no contexto da agricultura familiar. Organ Rurais Agroind. 2006; 8(3):334-43.

29. Torres FL, Torres ACM, Sobrinho FB, Dias TF, Nunes, EM. Inserção da agricultura familiar sustentável no PNAE: o caso da COOPAPI, Apodi-RN. Cad Agroecol. 2011; 6(2):1-6.

30. Medaets JP, Fonseca MFAC. Produção orgânica: regulamentação nacional e internacional. Brasília: Ministério do Desenvolvimento Agrário; 2005.

31. Brasil. Ministério da Saúde. Alimentos regionais brasileiros. Brasília: Ministério da Saúde; 2002 [acesso 2011 abr 16]. Disponível em: <http://nutricao. saude.gov.br/publicacoes.php>.

32. Brasil. Ministério da Saúde. Guia alimentar para a população brasileira: promovendo a alimentação saudável. Brasília: Ministério da Saúde; 2008.

33. Food and Agriculture Organization. Biodiversity for food and agriculture: Contributing for food security and sustainability in a changing world. Workshop; 2010 Apr 14-16; Rome: Food and Agriculture Organization; 2010 [cited 2013 Apr 30]. Available from: <http://www.fao.org/fileadmin/templates/ biodiversity_paia/PAR-FAO-book_Ir.pdf>.

Recebido em: 16/4/2013

Versão final em: 20/9/2013

Aprovado em: 10/10/2013 